\title{
Lithium Methyl Carbonate as a Reaction Product of Metallic Lithium and Dimethyl Carbonate
}

\author{
Guorong V. Zhuang*,Z, Hui Yang*, and Philip N. Ross, Jr.* \\ Environmental Energy Technologies Division \\ Lawrence Berkeley National Laboratory, Berkeley, CA 94720, USA \\ Kang $\mathrm{Xu}^{*}$ and $\mathrm{T}$. Richard Jow* \\ U. S. Army Research Laboratory, Adelphi, MD 20783, USA
}

\begin{abstract}
s
To improve the understanding of passive film formation on metallic lithium in organic electrolyte, we synthesized and characterized lithium methyl carbonate $\left(\mathrm{LiOCO}_{2} \mathrm{CH}_{3}\right)$, a prototypical component of the film. The chemical structure of this compound was characterized with Nuclear Magnetic Resonance (NMR) and Fourier Transform Infrared Spectroscopy (FTIR), and its thermal stability and decomposition pathway was studied by thermo-gravimetric analysis (TGA). The FTIR spectrum of chemically synthesized compound enabled us to resolve multiple products in the passive film on lithium in dimethyl carbonate (DMC). Lithium methyl carbonate is only one of the components, the others being lithium oxalate and lithium methoxide.

\footnotetext{
* Electrochemical Society Active Member

ZEmail: GVZhuang@lbl.gov
} 


\section{Introduction}

In a seminal paper, Aurbach et al. ${ }^{1}$ proposed that surface films formed on metallic lithium in propylene carbonate (PC) are not composed primarily of lithium carbonate, as suggested in earlier work by $\mathrm{Bro}^{2}$ and $\mathrm{Dey}^{3}$, but of lithium alkyl carbonates, $\mathrm{ROCO}_{2} \mathrm{Li}$, where $\mathrm{R}$ = alkyl group. This conclusion was reached based on ex-situ FTIR analysis of the surface layers, and comparison with spectra for reference compounds taken either from the literature or from compounds synthesized in the course of that study. In addition to $\mathrm{PC}$, some experiments were also described for the linear carbonate, diethylcarbonate (DEC), using the same procedures. It was reported that lithium metal is not passivated in DEC, but dissolves completely to form a dark brown solution. The products were isolated, analyzed by FTIR and reported to be a mixture of lithium ethylcarbonate $\left(\mathrm{CH}_{3} \mathrm{CH}_{2} \mathrm{OCO}_{2} \mathrm{Li}\right)$ and lithium ethoxide $\left(\mathrm{CH}_{3} \mathrm{CH}_{2} \mathrm{OLi}\right)$. This paper was pioneering and formed the basis for later work, especially by Aurbach and co-workers ${ }^{4,5}$. However, the actual IR spectra of the lithium alkyl carbonate reference compounds were not published either in reference 1 or in later work, only tabulations of frequencies and relative intensities $(\mathrm{s}=$ strong, $\mathrm{m}=$ medium, $\mathrm{w}=$ weak $)$ were given. Comparison of any experimental spectra with these tabulations is therefore very subjective.

In the present work, we present for the first time a complete IR spectrum for an important reference compound, lithium methyl carbonate, and relate this spectrum to that from the surface of metallic lithium immersed from dimethyl carbonate (DMC). The expected chemical reduction path of DMC on metallic Li surface, based on the studies by both Aurbach and co-workers ${ }^{1}$ and previous work from this laboratory ${ }^{6}$ is:

$$
2 \mathrm{CH}_{3} \mathrm{OCO}_{2} \mathrm{CH}_{3}+2 \mathrm{e}^{-}+2 \mathrm{Li}^{0} \rightarrow 2 \mathrm{LiOCO}_{2} \mathrm{CH}_{3}+\mathrm{CH}_{3} \mathrm{CH}_{3} \uparrow
$$




$$
\mathrm{CH}_{3} \mathrm{OCO}_{2} \mathrm{CH}_{3}+\mathrm{e}^{-}+\mathrm{Li}^{0} \rightarrow \mathrm{CH}_{3} \mathrm{OLi}+\mathrm{CH}_{3} \mathrm{OCO}^{\bullet} ?
$$

The reaction paths are, however, not completely understood, as only the solid products have been analyzed by spectroscopy (XPS or IR) and that product identification has not been unambiguous. It is also unclear whether these two reaction paths are in parallel, occurring simultaneously at different rates, or in series, i.e. methoxide is actually the product of a subsequent reduction of methyl carbonate, as in

$$
2 \mathrm{LiOCO}_{2} \mathrm{CH}_{3}+2 \mathrm{e}^{-}+2 \mathrm{Li}^{0} \rightarrow \mathrm{LiO}_{2} \mathrm{CCO}_{2} \mathrm{Li}+2 \mathrm{CH}_{3} \mathrm{OLi}
$$

We also present here data for the thermal decomposition of lithium methyl carbonate, which can be useful in understanding thermal studies of passive films on lithium or carbon anodes in lithium batteries ${ }^{7,8}$.

\section{Experimental}

Lithium methyl carbonate $\left(\mathrm{LiOCO}_{2} \mathrm{CH}_{3}\right)$ was synthesized at Army Research Laboratory, via a route modified from that used by Aurbach et al. ${ }^{1}$. The entire process of synthesis and purification was conducted in a dry-room with dew point below $-80{ }^{\circ} \mathrm{C}$. Methanol was first dried over $3 \AA \AA$ molecular sieve and then over neutral alumina until the moisture level was less than 5 ppm as determined by Karl-Fischer titration (MettlerToledo). Lithium hydride ( $\mathrm{LiH})$ was then slowly added to the excess amount of dried methanol $\left(\mathrm{CH}_{3} \mathrm{OH}\right)$ through a solid addition funnel at a rate to keep the reactant temperature below $40{ }^{\circ} \mathrm{C}$. At the end of the $\mathrm{LiH}$-addition the reactant was heated to reflux at ca. $80{ }^{\circ} \mathrm{C}$ for an hour. During the process additional amount of methanol was added to ensure that a clear methanolic solution of lithium methoxide $\left(\mathrm{LiOCH}_{3}\right)$ was obtained after cooling down to room temperature. Analytic grade carbon dioxide $\left(\mathrm{CO}_{2}\right)$ was introduced into the solution before passing through two gas bubblers containing concentrated 
sulfuric acid $\left(\mathrm{H}_{2} \mathrm{SO}_{4}\right)$. The reaction of $\mathrm{LiOCH}_{3}$ with $\mathrm{CO}_{2}$ is obviously exothermic and white crystal flakes was observed to precipitate. The $\mathrm{CO}_{2}$-injection was continued for several hours to ensure the completion of the $\mathrm{LiOCH}_{3}$ conversion, and the excess methanol was then evaporated. The obtained crystal was washed three times by the dried methanol to remove any possible remnants of unreacted $\mathrm{LiOCH}_{3}$. The final product was vacuum dried at room temperature.

The identification of $\mathrm{LiOCO}_{2} \mathrm{CH}_{3}$ as the synthesis product was conducted via ${ }^{1} \mathrm{H}$ and ${ }^{13} \mathrm{C}$-NMR (Oxford $400 \mathrm{MHz}$ NMR spectrometer) at University of Maryland. All deutered solvents used in NMR characterization were dried by $3 \AA$ molecular sieves. When trace amount of $\mathrm{LiOCO}_{2} \mathrm{CH}_{3}$ was dissolved in deutered dimethyl sulfoxide (DMSO- $\mathrm{d}_{6}$ ), the solution showed ${ }^{1} \mathrm{H}$-signal at $3.27 \mathrm{ppm}$ (singlet, for $\mathrm{C}(2) \mathbf{H}(\mathbf{1})_{3}-\mathrm{O}(3)$-) as well as ${ }^{13} \mathrm{C}$-signals at $51 \mathrm{ppm}$ (singlet, for $\mathbf{C}(2) \mathrm{H}(1)_{3}-\mathrm{O}(3)$-) and $157 \mathrm{ppm}$ (singlet, for $\mathbf{C}(\mathbf{1}) \mathrm{O}(3)-)$. Due to the limited solubility of $\mathrm{LiOCO}_{2} \mathrm{CH}_{3}$ in DMSO- $\mathrm{d}_{6}$, the observed carbonyl NMR signal was very weak. To confirm the presence of $\mathrm{sp}^{2}$-hybridized $\mathrm{O}(1) \mathrm{C}(1) \mathrm{O}(2)$ - structure and to avoid interference from the DMSO- $_{6}$ signals, we deliberately decomposed the $\mathrm{LiOCO}_{2} \mathrm{CH}_{3}$ in $\mathrm{D}_{2} \mathrm{O}$, and carried out further $\mathrm{NMR}$ measurements. The ${ }^{1} \mathrm{H}$-signal of decomposition mixture was shifted to $3.39 \mathrm{ppm}$, while a conspicuous ${ }^{13} \mathrm{C}$ peak was detected at 160 ppm, indicating that $\mathrm{CH}_{3} \mathrm{OD}$ and lithium carbonate $\left(\mathrm{Li}_{2} \mathrm{CO}_{3}\right)$ were formed as a result of hydrolysis. Therefore, the synthesized crystalline product was confirmed to be $\mathrm{LiOCO}_{2} \mathrm{CH}_{3}$.

A lithium (Li) foil (99.999\%, $1.5 \mathrm{~mm}$ thick) and dimethyl carbonate (DMC) (Aldrich, anhydrous $99 \%+, \mathrm{H}_{2} \mathrm{O}<20 \mathrm{ppm}$ ) were used for studying the surface chemical reaction of $\mathrm{Li}$ and DMC. The experiments were conducted in Ar-filled glove box, with $\mathrm{O}_{2}$ 
content $<1 \mathrm{ppm}$ and $\mathrm{H}_{2} \mathrm{O}$ content $<2 \mathrm{ppm}$. The surface reaction was initiated by scraping off the native surface layer on metallic Li foil while in DMC solution, followed by exposure of the fresh surface to DMC for one minute. After removing the Li foil from the DMC solution, the excess DMC was allowed to evaporate from the sample surface in the glovebox prior to transferring to the FTIR spectrometer.

FTIR analysis of all solid samples, including the solid remnants from $\mathrm{LiOCO}_{2} \mathrm{CH}_{3}$ after TGA experiment and the surface film on metallic $\mathrm{Li}$, were conducted with the attenuated total internal reflection (ATR) method described in previous publications ${ }^{9,10}$. The FTIR measurements were performed in a He environment, and under no circumstances were the sample exposed to air. All the spectra were acquired at a resolution of $4 \mathrm{~cm}^{-1}$ and summed over 512 scans.

A Thermo-gravimetric Analyzer (TGA model 2960, TA Instruments) and a Fourier Transform Infrared (FTIR) Spectrometer (Nexus 470, Nicolet) equipped with a temperature controlled transmission gas cell were used for thermal analysis by dynamic TGA-FTIR. Thermal analysis by TGA-FTIR measures the change in sample weight as a function of temperature at a heating rate of $10 \mathrm{~K} \cdot \mathrm{min}^{-1}$ while simultaneously analyzing the composition of volatile components evolved from sample as a result of thermal decomposition. The gas phase products were eluted to the FTIR gas cell by Ar carrier gas at a flow rate of $220 \mathrm{ml} \cdot \mathrm{min}^{-1}$. The FTIR spectra were continuously acquired at a resolution of $4 \mathrm{~cm}^{-1}$ and summed over 32 scans during the thermo-gravimetric (TG) measurements. The TGA and FTIR are coupled via quartz capillary array. During the analysis, both FTIR gas cell and capillary array were maintained at $200{ }^{\circ} \mathrm{C}$ to prevent gas absorption or condensation on gas cell and capillary walls. To ensure an inert atmosphere 
during the thermal analysis, the TGA was housed in argon (Ar) atmosphere glovebag. The optical path was sufficiently purged that the infrared signal from residual moisture and $\mathrm{CO}_{2}$ was much smaller than that from the reaction products. The inert atmosphere working condition of the TGA-FTIR apparatus was checked using thermal analysis copper oxalate following work of Mullens et al. ${ }^{11}$. All the samples were transferred from an $\mathrm{Ar}$ atmosphere glovebox to the TGA sample chamber using a portable vacuum carrier with no transient air exposure. The mass loss measurements reported in this work have an accuracy of $\pm 1 \%$.

\section{Results and Discussion}

The purity of the synthesized lithium methyl carbonate is confirmed by the FTIR spectrum in Fig.1, which is absent of any form of crystallized water, lithium hydroxide (LiOH) or absorbed water as indicated by the featureless spectral region above $3000 \mathrm{~cm}^{-1}$. The amount of lithium carbonate $\left(\mathrm{Li}_{2} \mathrm{CO}_{3}\right)$ in the sample is negligible as well. The molecular structure of lithium methyl carbonate was obtained from an ab-initio quantum chemical calculation at the $\mathrm{HF} / 6-31 \mathrm{G}(\mathrm{d}, \mathrm{p})$ level $^{12}$ for the two conformations shown in Fig.1. The systematic error in calculated vibrational frequencies at the HF level was corrected by using empirical scaling factor of $0.8929^{13}$. Calculated vibrational frequencies based on the converged geometries are tabulated in Table 1. Our calculated vibrational frequencies are very similar to those reported earlier for the same molecular conformations $^{14}$ using essentially the same computational methodology. Therefore, emphasis here will be placed on the assignment of our experimental vibrational modes in reference to calculations. Table 1 shows that the vibrational frequencies based on the dimer yields much better agreement with the experimental data than the monomer. 
Specifically, the calculated frequencies of $\mathrm{O}(1) \mathrm{C}(1) \mathrm{O}(2)$ asymmetric stretching mode $\left(1659 \mathrm{~cm}^{-1}\right.$ vs. $\left.1652 \mathrm{~cm}^{-1}\right), \mathrm{O}(1) \mathrm{C}(1) \mathrm{O}(2)$ symmetric stretching mode $\left(1482 \mathrm{~cm}^{-1}\right.$ vs. 1479 $\left.\mathrm{cm}^{-1}\right)$, especially $\mathrm{O}(1) \mathrm{C}(1) \mathrm{O}(2) \mathrm{O}(3)$ asymmetric stretching mode $\left(1377 \mathrm{~cm}^{-1}\right.$ vs. $1370 \mathrm{~cm}^{-}$ ${ }^{1}$ ) in dimer, are shifted closer to those experimentally measured ones, although out-ofplane bending mode $\left(835 \mathrm{~cm}^{-1}\right.$ vs. $\left.822 \mathrm{~cm}^{-1}\right)$ of $\mathrm{O}(1) \mathrm{C}(2) \mathrm{O}(2) \mathrm{O}(3)$ is not sensitive to dimerization. The shift of the $\mathrm{O}(1) \mathrm{C}(1) \mathrm{O}(2)$ asymmetric mode in the dimer to higher wavenumber is a measure of bond delocalization of the $\mathrm{O}(1) \mathrm{C}(1) \mathrm{O}(2)$ carbonyl functionality. With respect to the original tabulation of IR bands for lithium methyl carbonate reported by Behrendt et al. ${ }^{15}$, and repeated in the tabulation by Aurbach et al. ${ }^{1}$, the agreement with our experimental spectrum and band assignment is generally very close, with two notable differences. In the original tabulation, the strong bands near 1640 and $1100 \mathrm{~cm}^{-1}$ were reported to be doublets, whereas our spectrum clearly shows sharp single vibrational bands. Based on our quantum chemical modeling, we suggest that the splitting observed by Behrendt et al. is from residual methanol, which partially solvates (some) of the lithium ions and shifts the associated $\mathrm{O}(1) \mathrm{C}(1) \mathrm{O}(2)$ and $\mathrm{C}(2) \mathrm{O}(3) \mathrm{C}(1)$ asymmetric stretching modes. Consistent with this is the exact agreement at $822 \mathrm{~cm}^{-1}$ for the $\mathrm{O}(1) \mathrm{C}(2) \mathrm{O}(2) \mathrm{O}(3)$ out-of-plane bending mode, which the calculation showed is not sensitive to dimerization (i.e. lithium ion coordination). The weak peaks at about 1200 $\mathrm{cm}^{-1}, 950 \mathrm{~cm}^{-1}$ and $850 \mathrm{~cm}^{-1}$ are originated from combination of fundamental vibration modes.

Having described the molecular structure and the vibrational modes in the infrared spectrum of $\mathrm{LiOCO}_{2} \mathrm{CH}_{3}$ in some detail, we now discuss the surface film formed as a result of the chemical reaction between metallic lithium and DMC. The FTIR 
spectrum of the resulting surface layer is shown in Figure $2 \mathrm{~b}$. The relatively strong peak centered at $1670 \mathrm{~cm}^{-1}$ is qualitatively an indication of a carbonyl group on the surface with bond order of 1.5 , i.e. the extent of delocalization of carbonyl group, but clearly this feature is not as sharp as that in reference compound, $\mathrm{LiOCO}_{2} \mathrm{CH}_{3}$ (Fig. 2 a). All the spectral features attributable to $\mathrm{LiOCO}_{2} \mathrm{CH}_{3}$ can be seen in the spectrum from the surface layer. However, it is also clear, as evidenced by the subtle differences in peak positions and peak broadening, by a new peak at $1075 \mathrm{~cm}^{-1}$ and by additional peaks $\left(2772 \mathrm{~cm}^{-1}\right.$, $2805 \mathrm{~cm}^{-1}, 2920 \mathrm{~cm}^{-1}$ ) in the $\mathrm{CH}$ stretching region, that lithium methyl carbonate is not the only reaction product on the surface. The latter features compare well to those of a $\mathrm{LiOCH}_{3}$ reference compound (Fig. 2 c), although there is noticeable shift in C-O-Li stretching mode $\left(1042 \mathrm{~cm}^{-1}\right.$ in bulk vs. $1075 \mathrm{~cm}^{-1}$ on surface) particularly. A possible explanation would be that the $\mathrm{LiOCH}_{3}$ is a $\mathrm{CH}_{3} \mathrm{O}^{-}$anion chemisorbed on the $\mathrm{Li}$ surface, which would result in a longer $\mathrm{Li}-\mathrm{O}$ bond than in bulk $\mathrm{LiOCH}_{3}$ and a $\mathrm{C}-\mathrm{O}$ frequency shift of the surface versus bulk methoxide. There is also imperfect matching between the reference compound $\mathrm{LiOCH}_{3}$ and the surface sample in the C-H region. Specifically, a new $2772 \mathrm{~cm}^{-1}$ feature appears to superimpose on $2800 \mathrm{~cm}^{-1}$ peak and peak intensity transfer from $2844 \mathrm{~cm}^{-1}$ to $2923 \mathrm{~cm}^{-1}$. These spectral features are indications that there exist other forms of the methoxy functional group $\left(-\mathrm{OCH}_{3}\right)$ in addition to $\mathrm{Li} \cdots \mathrm{OCH}_{3}$. Quantum chemical calculations indicate the observed frequency shift and intensity redistribution of the methoxy group are in consistent with two methoxy groups within a single molecule vibrating in-phase and out-of-phase. Although we could not find an improved match using other methoxy-containing reference compounds, some candidate molecules are suggested from the reaction mechanism discussed below. 
In our earlier X-ray photoemission spectroscopy (XPS) study ${ }^{6}$ of the surface reaction of metallic lithium with DMC, we clearly identified lithium methyl carbonate as one of the initial reaction products. However, as the temperature was raised, we could not clearly assign a molecular identity to the additional and/or subsequent reaction products. Other chemical shifts in the $\mathrm{C} 1 \mathrm{~s}$ binding energies were assigned less specifically either to carbons with two oxygen ligands (either carboxylate or oxalate) or carbon with one oxygen ligand (e. g. - $\mathrm{OCH}_{2}$ - or $-\mathrm{OCH}_{3}$ ), while the shifts in the $\mathrm{O} 1 \mathrm{~s}$ binding energy lay in a broad range between $532 \sim 533 \mathrm{eV}$ covered by a large class of oxygen-containing compounds. A similar approach to the assignment of $\mathrm{C} 1 \mathrm{~s}$ chemical shifts for the passive films formed on carbon anodes was employed by K. Edström et. al. ${ }^{16}$. In essence, aside from lithium methyl carbonate, any or combination of lithium methoxide, lithium oxalate and lithium carboxylate would give rise to the $\mathrm{C} 1 \mathrm{~s}$ and $\mathrm{O} 1 \mathrm{~s}$ binding energies observed experimentally. In this study using FTIR spectroscopy, we are able to obtain greater chemical specificity. The presence of a lithium carboxylate could be ruled out readily from absence of characteristic vibrational modes at ca. $1580 \mathrm{~cm}^{-1}$. Thus, carbons with two oxygen ligands (e.g. C1s peak at $288 \mathrm{eV}$ ) could be attributed primarily to lithium oxalate $\left(\mathrm{Li}_{2} \mathrm{C}_{2} \mathrm{O}_{4}\right)$. The $\mathrm{OCO}$ asymmetric and symmetric stretching modes of bulk lithium oxalate (Fig.2 d) are at $1645 \mathrm{~cm}^{-1}$ and $1327 \mathrm{~cm}^{-1}$, respectively, while the OCO deformation mode is at $748 \mathrm{~cm}^{-1}$. Both stretching modes partially overlap with lithium methyl carbonate vibrational modes in $1660 \mathrm{~cm}^{-1}$ and $1350 \mathrm{~cm}^{-1}$ region. What distinguishes the lithium oxalate from other candidate lithium compounds is the OCO deformation mode at 774 $\mathrm{cm}^{-1}$, which is attributed to two OCO deformation modes out of phase. This peak shifts to $749 \mathrm{~cm}^{-1}$ for surface species due to the fact that Li-O bond strength differs in bulk and 
surface lithium oxalate. Consistent with our previous Ultrahigh Vacuum (UHV)-XPS study of metallic lithium and DMC (and DEC), there is no spectral evidence of $\mathrm{Li}_{2} \mathrm{CO}_{3}$ as a chemical reduction product.

It is perhaps unexpected that lithium methyl carbonate, lithium methoxide and lithium oxalate coexist on the metallic Li surface, since only the formation of lithium methyl carbonate is thermodynamically favorable based on quantum chemistry calculations by Wang and Balbuena ${ }^{17}$. However, the reaction paths leads to those products identified by FTIR and XPS could be rationalized based on following proposed multiple reaction routes $4-6$.

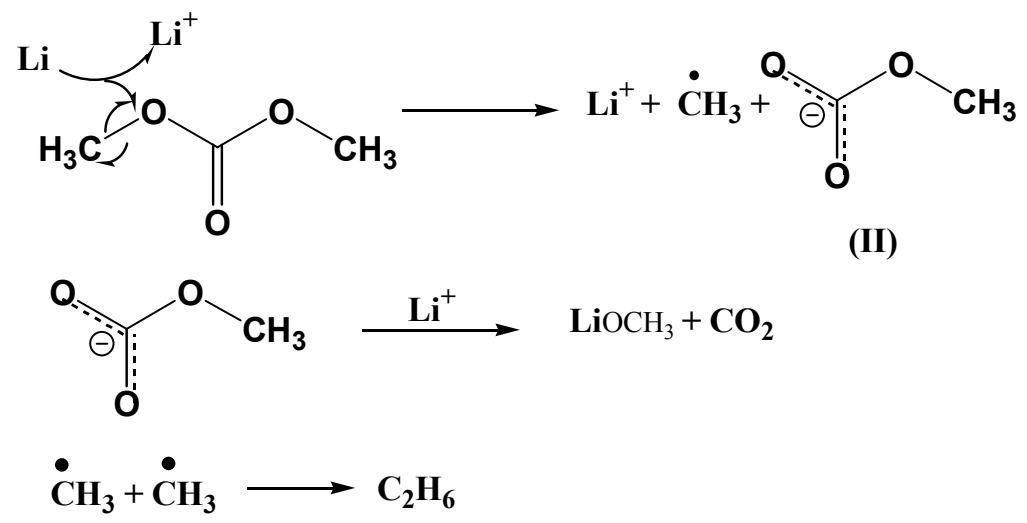

We propose that instantaneously upon contact, a direct electron transfer occurs between lithium metal electrode and DMC, which, experiencing a symmetrical cleavage of the ester linkage in DMC, generates a rather unstable methyl radical $\left(\mathrm{CH}_{3}{ }^{\bullet}\right)$ and a relatively stable anion (with $\mathrm{R}=$ methyl, i.e. lithium methyl carbonate), as shown in (4a). The fate of $\mathrm{CH}_{3} \bullet$ might have multiple ends, one of which is the recombination as shown in (4c) and produces ethane, while the anion (II), serving as a stable intermediate, could rearrange into $\mathrm{CO}_{2}$ and $\mathrm{LiOCH}_{3}(4 \mathrm{~b})$. On the other hand, a competitive process that could proceed simultaneously with route 4 is characterized by a symmetrical cleavage on the acyl side of ester linkage in DMC, generating a rather stable anion $\left(\mathrm{CH}_{3} \mathrm{O}^{-}\right)$and also a stable acyl 
radical, as shown by route (5a). The latter could attack a second DMC molecule, resulting in various oxalate moieties (III) (V), along with propagation of radical $\mathrm{CH}_{3} \mathrm{O} \bullet$.<smiles>COC(=O)[C@H]([18O])OC</smiles>

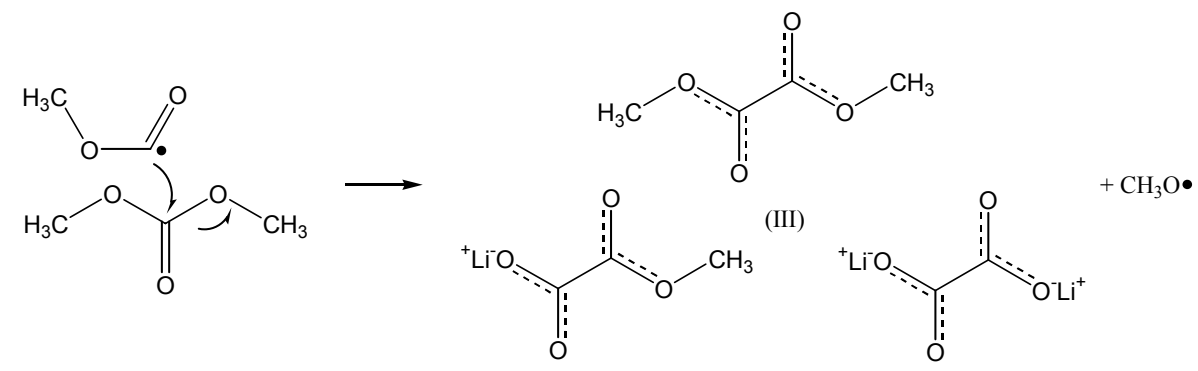

(V)
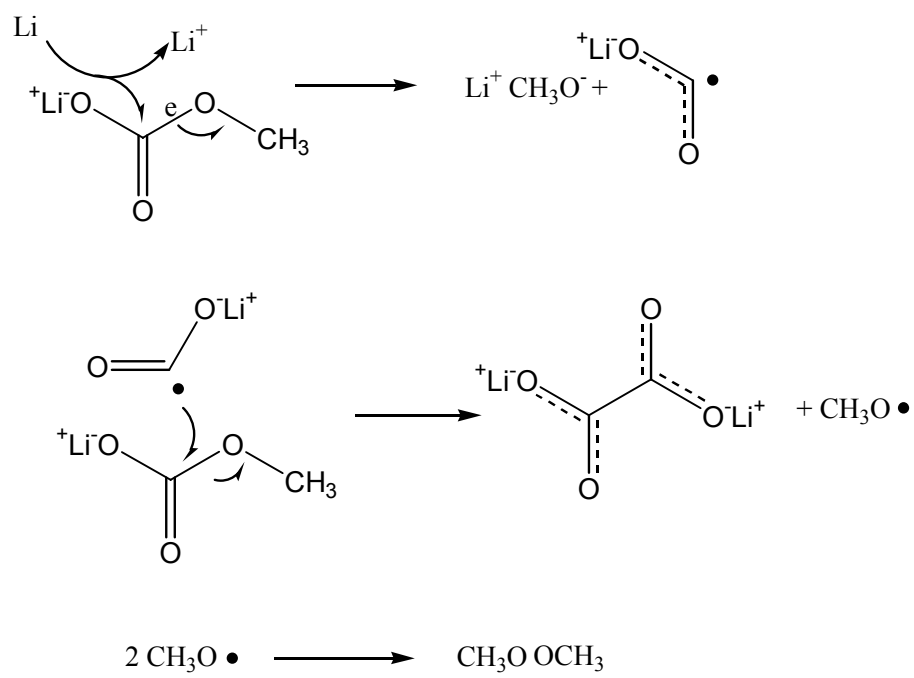

The possibility of the continued reduction of lithium methylcarbonate (II) cannot be excluded, especially where this species is closer to lithium substrate. As route 4 and 5 show, this equivalent of a two-electron reduction process of DMC would eventually lead to a surface layer that entirely consists of lithium oxalate and methoxide. Since the radical species $\mathrm{CH}_{3} \mathrm{O} \bullet$ has rather long lifetime, the formation of dimethyl peroxide, $\mathrm{CH}_{3} \mathrm{O}-\mathrm{OCH}_{3}$, is also plausible. Unfortunately, it is very difficult to identify dimethyl peroxide by IR spectroscopy due to its high molecular symmetry. However, the spectral 
evidence of two methoxy groups in a molecule presented earlier supports the aboveproposed fate of $\mathrm{CH}_{3} \mathrm{O}$, e.g. methyl esters of oxalic acid (route 6)

We further studied the thermal decomposition of lithium methyl carbonate by dynamic TGA-FTIR. The mass loss profiles during thermal decomposition are presented in Fig. 3. The most significant mass loss (ca. $45 \%$ ) was observed in the temperature range of $440 \mathrm{~K}-540 \mathrm{~K}$. The derivative thermo-gravimetric (DTG) curve further revealed that the mass loss occured in two steps, at $480 \mathrm{~K}$ and $520 \mathrm{~K}$, respectively. Two correspondingly well-defined endotherms in the derivative thermal analysis (DTA) profile also indicated two-step thermal decomposition reaction pathway. In order to identify the thermal decomposition pathway associated with the DTG profile, the compositions of the gaseous decomposition products were continuously monitored by gas phase FTIR. In the temperature range from $300 \mathrm{~K}$ up to $700 \mathrm{~K}, \mathrm{CO}_{2}$ and dimethyl ether $\left(\mathrm{CH}_{3} \mathrm{OCH}_{3}\right)$ are the only species detected. The characteristic asymmetric stretching and bending mode of $\mathrm{CO}_{2}$ appear at $2359 \mathrm{~cm}^{-1}$ and $668 \mathrm{~cm}^{-1}$, respectively, while OCO asymmetric stretching mode in $\mathrm{CH}_{3} \mathrm{OCH}_{3}$ giving rise to a strong peak at $1192 \mathrm{~cm}^{-1}$. The IR intensity of peaks at $2359 \mathrm{~cm}^{-1}$ and $1192 \mathrm{~cm}^{-1}$ in representative of $\mathrm{CO}_{2}$ and $\mathrm{CH}_{3} \mathrm{OCH}_{3}$ respectively, was plotted as a function of temperature along with DTG profile in Fig. 4, panel A. Clearly, only $\mathrm{CO}_{2}$ evolution is detected in gas phase FTIR during the first endothermic thermal decomposition reaction starting at about $400 \mathrm{~K}$ and reaching maximum at ca. $480 \mathrm{~K}$. The most plausible reaction path consistent with experimental evidence would be

$$
\mathrm{CH}_{3} \mathrm{OCOOLi} \rightarrow \mathrm{CH}_{3} \mathrm{OLi}+\mathrm{CO}_{2}
$$


since the reverse direction of this reaction, as observed during the synthesis of lithium methyl carbonate from lithium methoxide, was exothermic. This reaction would leave $\mathrm{CH}_{3} \mathrm{OLi}$ as a solid residue, which was confirmed in post mortem FTIR analysis, as we will describe below.

As temperature reached $490 \mathrm{~K}$, at the onset of the second endothermic peak centered at $525 \mathrm{~K}$, a new gaseous product, $\mathrm{CH}_{3} \mathrm{OCH}_{3}$ starts to appear, concomitant with increased $\mathrm{CO}_{2}$ evolution. Judged by the two well-resolved peaks in DTA, it appears that the reaction (7) continues while another thermal decomposition is initiated. From $580 \mathrm{~K}$ to $700 \mathrm{~K}$, no gaseous products were observed by FTIR, i.e. the thermal decomposition of lithium methyl carbonate is completed at about $580 \mathrm{~K}$. At the end of TGA experiment, there remains $45.6 \%$ of the starting mass. The FTIR analysis performed on this solid residue immediately after TGA is shown in panel B of Fig. 4. The most intense peak at $1500 \mathrm{~cm}^{-1}$ region and a sharp peak at $863 \mathrm{~cm}^{-1}$ are characteristic of $\mathrm{Li}_{2} \mathrm{CO}_{3}$. The presence of $\mathrm{LiOCH}_{3}$ is also revealed by vibrational modes at $1050 \mathrm{~cm}^{-1}$ along with $2929 \mathrm{~cm}^{-1}$, $2850 \mathrm{~cm}^{-1}$ and $2793 \mathrm{~cm}^{-1}$. Since thermal decomposition (7) produces $\mathrm{LiOCH}_{3}$ as sole solid product that is known to be thermally stable up to $730 \mathrm{~K}$ (unpublished result from our lab), $\mathrm{Li}_{2} \mathrm{CO}_{3}$ is most probably generated from another thermal decomposition path proceeding in parallel, i.e. competitively to (7). This new competitive thermal decomposition path is probably associated with the generation $\mathrm{CO}_{2}$ and $\mathrm{CH}_{3} \mathrm{OCH}_{3}$ in temperature range from $490 \mathrm{~K}-580 \mathrm{~K}$. We suggest the reaction, which is consistent with these gaseous products as well as $\mathrm{Li}_{2} \mathrm{CO}_{3}$ is

$$
2 \mathrm{CH}_{3} \mathrm{OCOOLi} \rightarrow \mathrm{CO}_{2}+\mathrm{CH}_{3} \mathrm{OCH}_{3}+\mathrm{Li}_{2} \mathrm{CO}_{3}
$$


By deconvoluting DTG curve in Fig. 3, it could be estimated that stage I thermal decomposition, i.e. reaction path (7), accounts for $70 \%$ of the total mass loss. $\mathrm{LiOCH}_{3}$ as the solid product would constitute $32.4 \%$ of the original mass. The remaining $30 \%$ of lithium methyl carbonate in stage II thermal decomposition following reaction path (8) would constitute $13.5 \%$ of the original mass. Thus, the actual remaining mass of $45.6 \%$ and the solid product analysis by FTIR is consistent with is consistent with the proposed parallel path thermal decomposition mechanism.

It is of interest to compare the present result on thermal decomposition of lithium methyl carbonate with that of the passive film formed on a $\mathrm{Ni}$ electrode in $\mathrm{LiPF}_{6} /$ ethylene carbonate (EC):DMC(1:1) ${ }^{7}$. In the cited experiment, the Ni electrode was immersed from the electrolyte after ten cycles of lithium deposition/dissolution, washed with dimethoxyethane (DME), and then placed in a temperature programmed desorptionmass spectrometer (TPD-MS) apparatus. $\mathrm{CO}_{2}$ evolution profile measured as a function of temperature at a heating rate of $10{ }^{\circ} \mathrm{C} \cdot \mathrm{min}^{-1}$ was the same as in our TGA-FTIR measurement. The $\mathrm{CO}_{2}$ evolved in a single TPD peak centered at about $130{ }^{\circ} \mathrm{C}$ (ca. 400 K) is attributed to the decomposition of "organic carbonate surface films". In the present study, we have shown that the thermal decomposition of one such organic carbonate, lithium methyl carbonate, produces a broad $\mathrm{CO}_{2}$ evolution peak centered at about $530 \mathrm{~K}$, more than $100 \mathrm{~K}$ higher than that for the passive film formed in $\mathrm{LiPF}_{6} / \mathrm{EC}: \mathrm{DMC}(1: 1)$. From this comparison alone, we would suggest that the organic carbonate present in the film is not lithium methyl carbonate, which would form from the selective reduction of DMC versus EC, but another alkyl carbonate decomposing at a lower temperature. In fact, we have other evidence supporting this suggestion. First, we have recently published 
results $^{18}$ from FTIR analysis of the composition of the passive formed on a Ni electrode cycled through lithium deposition/dissolution in $1.2 \mathrm{M} \mathrm{LiPF}_{6} / \mathrm{EC}$ : ethyl methyl carbonate (EMC) (3:7), i.e. a very similar experiment to that of Ota et al.. We found that unlike the case here that the film is entirely organic carbonate, specifically lithium ethylene dicarbonate, from the selective reduction of EC. In related as yet unpublished experiments, we also found that the thermal decomposition temperature for the dicarbonate is about $100 \mathrm{~K}$ lower than that of lithium methyl carbonate. However, the composition of surface films has a close relation to relative ratio of EC-DMC. Lithium methyl carbonate could be a surface product as proposed by Aurbach et al.. ${ }^{19}$

\section{Conclusions}

The reaction of metallic lithium with the dimethyl carbonate (DMC), a prototypical lithium battery electrolyte component, is more complex than indicated in previous work. Solid products forming on the surface identified by FTIR analysis include not only lithium methyl carbonate and lithium methoxide identified previously, but also lithium oxalate and possibly methyl esters of oxalic acid. A reaction path is suggested where methoxide and oxalate are formed by further reaction of lithium methyl carbonate with radical intermediates. Our dynamic TGA-FTIR study also suggests that lithium methyl carbonate has greater thermal stability than supposed previously.

\section{Acknowledgement}

This work was supported by the Office of Advanced Automotive Technologies, and the Office of FreedomCAR and Vehicle Technologies, of the U.S. Department of Energy under contract Nos. DE-AC02-05CH11231 (LBNL) and DE-AI01-99EE5061 (ARL), respectively. 


\section{References}

1. D. Aurbach, M. L. Daroux, P. W. Faguy and E. Yeager, J. Electrochem. Soc., 134, 1611 (1987).

2. R. Selim and P. Bro, J. Electrochem. Soc., 121, 1467 (1974).

3. A. N. Day, B. P. Sullivan, J. Electrochem. Soc., 117, 222 (1970).

4. D. Aurbach, A. Zaban, A. Shechter, Y. Ein-Eli, E. Zinigrad and B. Markovsky, J. Electrochem. Soc., 142, 2873 (1995).

5. D. Aurbach, M. Moshkovich, Y. Cohen and A. Schechter, Langmuir, 15, 2947 (1999).

6. G. Zhuang, Y. Chen and P. N. Ross, Langmuir, 15, 1470 (1999).

7. H. Ota, Y. Sakata, Y Otake, K. Shima, M. Ue and J. Yamaki, J. Electrochem. Soc., 151, A1778 (2004).

8. A. Du Pasquier, F. Disma, T. Bowmer, A. S. Gozdz, G. Amatucci and J-M. Tarascon, J. Electrochem. Soc., 145, 472 (1998).

9. G. V. Zhuang and P.N. Ross, Jr., Electrochim. Solid-State Lett., 6, A136 (2003).

10. S.-W. Song, G. V. Zhuang and P.N. Ross, Jr., J. Electrochem. Soc., 151, A1162 (2004).

11. J. Mullens, A. Vos, R. Carleer, J. Yperman and L. C. Van Poucke, Thermochimica Acta, 207, 337 (1992).

12. Frisch, M. J.; Trucks, G. W.; Schlegel, H. B.; Scuseria, G. E.; Robb, M. A.; Cheeseman, J. R.; Zakrzewski, V. G.; Montgomery, J. A.; Stratmann, R. E.; Burant, J. C.; Dapprich, S.; Millam, J. M.; Daniels, A. D.; Kudin, K. N.; Strain, O. F. M. C.; Tomasi, J.; Barone, B.; Cossi, M.; Cammi, R.; Mennucci, B.; Pomelli, C.; Adamo, C.; 
Clifford, S.; Ochterski, J.; Petersson, G. A.; Ayala, P. Y.; Cui, Q.;Morokuma, K.;

Malick, D. K.; Rabuck, A. D.; Raghavachari, K.; Foresman, J. B.; Ciolovski, J.; Ortiz, J. V.; Stefanov, V. V.; Liu, G.; Liashensko, A.; Piskorz, P.; Komaroni, I.; Gomperts, R.; Martin, R. L.; Fox, D. J.; Keith, T.; Al-Laham, M. A.; Peng, C. Y.; Nanayakkara, A.; Gonzalez, C.; Challacombe, M.; Gill, P. M. W.; Johnson, B.; Chen, W.; Wong, M. W. Andres, J. L.; Head-Gordon, M.; Replogle, E. S.; Pople, J. A. Gaussian 98, Revision A.11.3; Gaussian, Inc.: Pittsburgh PA, 1998.

13. J. A. Pople, R. Krishnan, H. Schlegel and J. S. Binkley, Int. J. Quantum Chem. Symp. 13, 225 (1979).

14. S. Matsuta, T. Asada and K. Kitaura, J. Electrochem. Soc., 147, 1695 (2000).

15. V. W. Behrendt, G. Gattow and M. Drager, Z. Anorg. Allg. Chem., 397, 237 (1973).

16. M. Herstedt, D. P. Abraham, J. B. Kerr and K. Edström, Electrochimica Acta, 49, 5097 (2004).

17. Y. Wang, P. B. Balbuena, Int. J. Quantum Chem., 102, 724 (2005).

18. G. V. Zhuang, K. Xu, H. Yang, T. R. Jow and P. N. Ross, Jr., J. Phys. Chem. B, 109, 17567(2005).

19. D. Aurbach, A. Schechter, Electrochim. Acta, 46, 2395(2001). 


\section{Figure Captions}

Figure 1. FTIR spectrum of chemically synthesized lithium methylcarbonate $\left(\mathrm{CH}_{3} \mathrm{OCO}_{2} \mathrm{Li}\right)$. The molecular structures of lithium methyl carbonate $\left(\mathrm{CH}_{3} \mathrm{OCO}_{2} \mathrm{Li}\right)$ and its dimerized form obtained from ab-initio MO calculation at HF/6-31G(d,p) level are shown in inset (a) and (b), respectively.

Figure 2. FTIR spectra of lithium methyl carbonate (a); surface film formed by reacting metallic Li with DMC (b), lithium methoxide (c) and lithium oxalate (d).

Figure 3. TG, derivative thermal analysis (DTA), derivative thermo-gravimetric (DTG) profiles of lithium methyl carbonate obtained at a heating rate of $10 \mathrm{~K} \cdot \mathrm{min}^{-1}$ in inert gas (Ar) environment.

Figure 4. Panel A: gas evolution from thermal decompositions of lithium methyl carbonate as a function of temperature (inset: FTIR spectrum of $\mathrm{CO}_{2}$ and $\mathrm{CH}_{3} \mathrm{OCH}_{3}$ mixture at $560 \mathrm{~K}$ ); Panel B: FTIR spectrum of solid residue of lithium methyl carbonate after completing the TG analysis at $700 \mathrm{~K}$. 
Table 1. Comparison of experimental and calculated vibrational frequencies of lithium methyl dicarbonate single molecule and dimer

\begin{tabular}{cccl}
\hline Experimental & $\begin{array}{c}\text { Monomer } \\
\text { Calculated } \\
\left(\mathrm{cm}^{-1}\right)\end{array}$ & $\begin{array}{c}\text { Dimer } \\
\text { Calculated } \\
\left(\mathrm{cm}^{-1}\right)\end{array}$ & \multicolumn{1}{c}{ Assignment } \\
\hline 2998 & 2960 & 2960 & $\mathrm{C}(2) \mathrm{H}_{3}$ asym. str. \\
2958 & 2949 & 2948 & $\mathrm{C}(2) \mathrm{H}_{2}$ asym. str. \\
2868 & 2876 & 2876 & $\mathrm{C}(2) \mathrm{H}_{3}$ sym. str. \\
1652 & 1597 & $\mathbf{1 6 5 9}$ & $\mathrm{O}(1) \mathrm{C}(1) \mathrm{O}(2)$ asym. str. \\
1479 & 1497 & $\mathbf{1 4 8 2}$ & $\mathrm{O}(1) \mathrm{C}(1) \mathrm{O}(2)$ sym.str. $+\mathrm{C}(2) \mathrm{H}_{3}$ umbrella \\
1465 & 1459 & 1458 & $\mathrm{CH}$ asym. deformation \\
1452 & 1394 & $\mathbf{1 3 7 7}$ & $\mathrm{O}(1) \mathrm{C}(1) \mathrm{O}(2) \mathrm{O}(3)$ asym. str. $+\mathrm{C}(2) \mathrm{H}_{3}$ \\
$1370($ broad $)$ & & & sym. deformation \\
1350 & 1128 & $\mathbf{1 1 4 3}$ & $\mathrm{C}(2) \mathrm{O}(3) \mathrm{C}(1)$ asym. str. \\
1096 & 835 & $\mathbf{8 3 5}$ & $\mathrm{O}(1) \mathrm{C}(1) \mathrm{O}(2) \mathrm{O}(3)$ out of plane bending \\
822 & & &
\end{tabular}




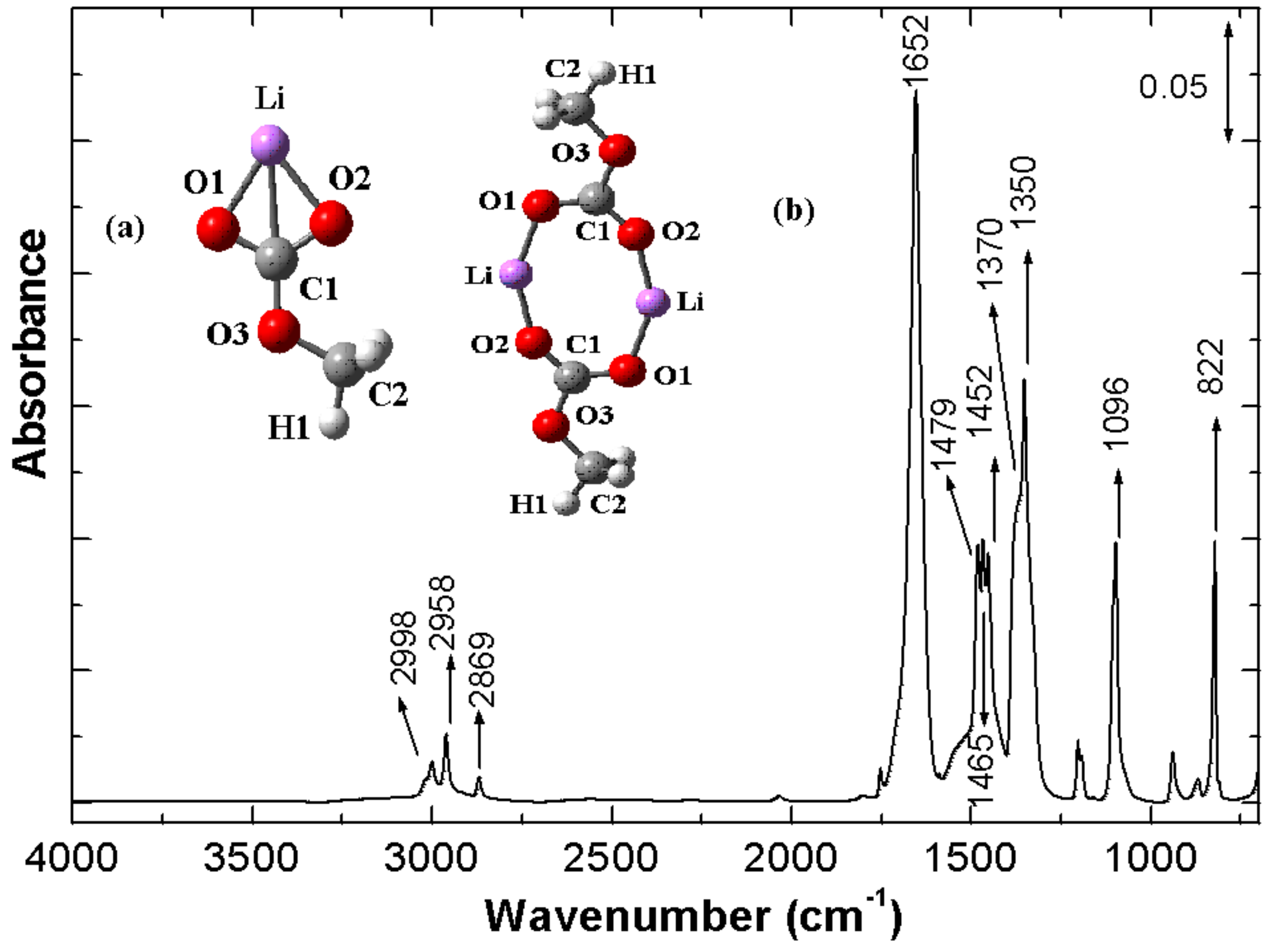




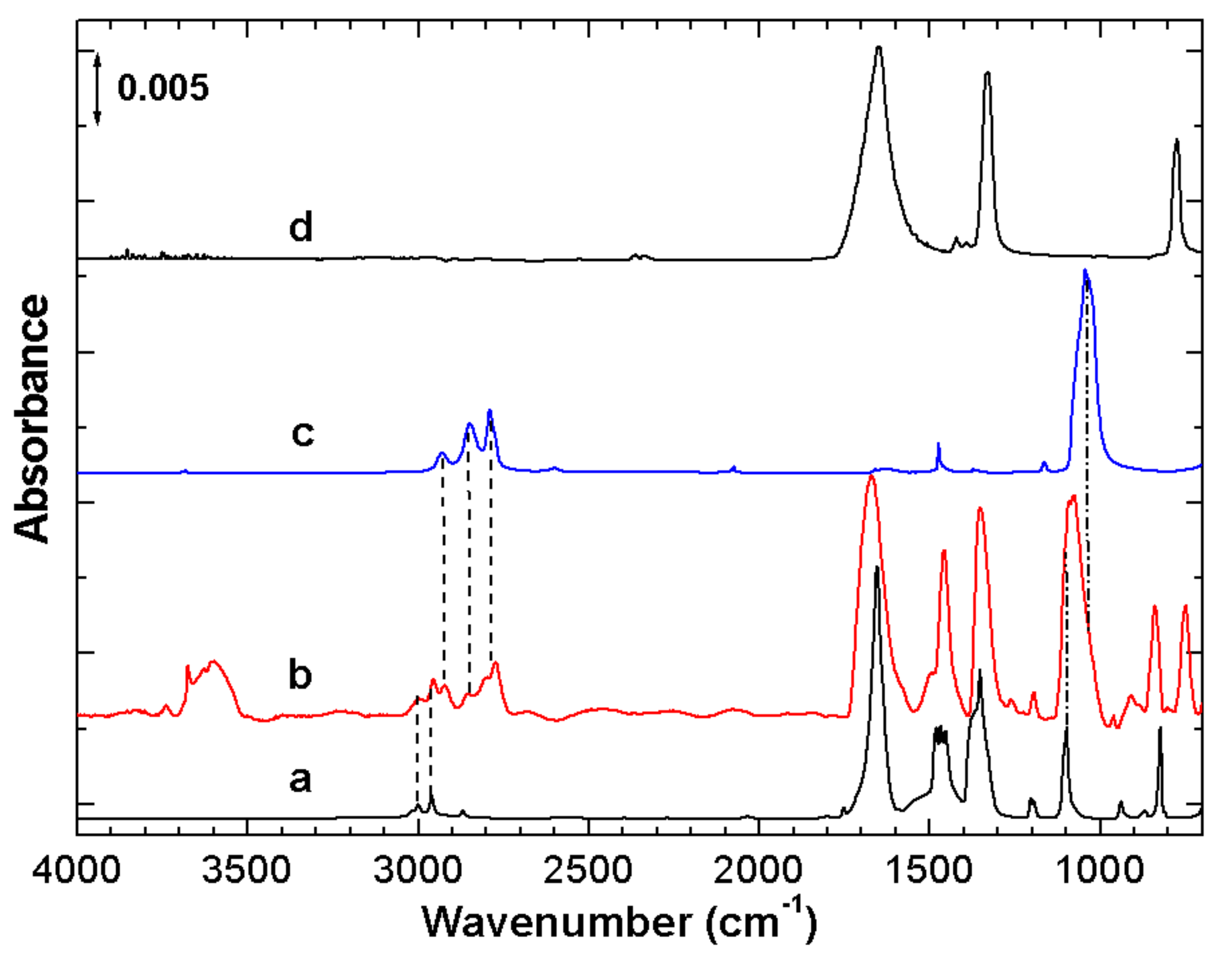




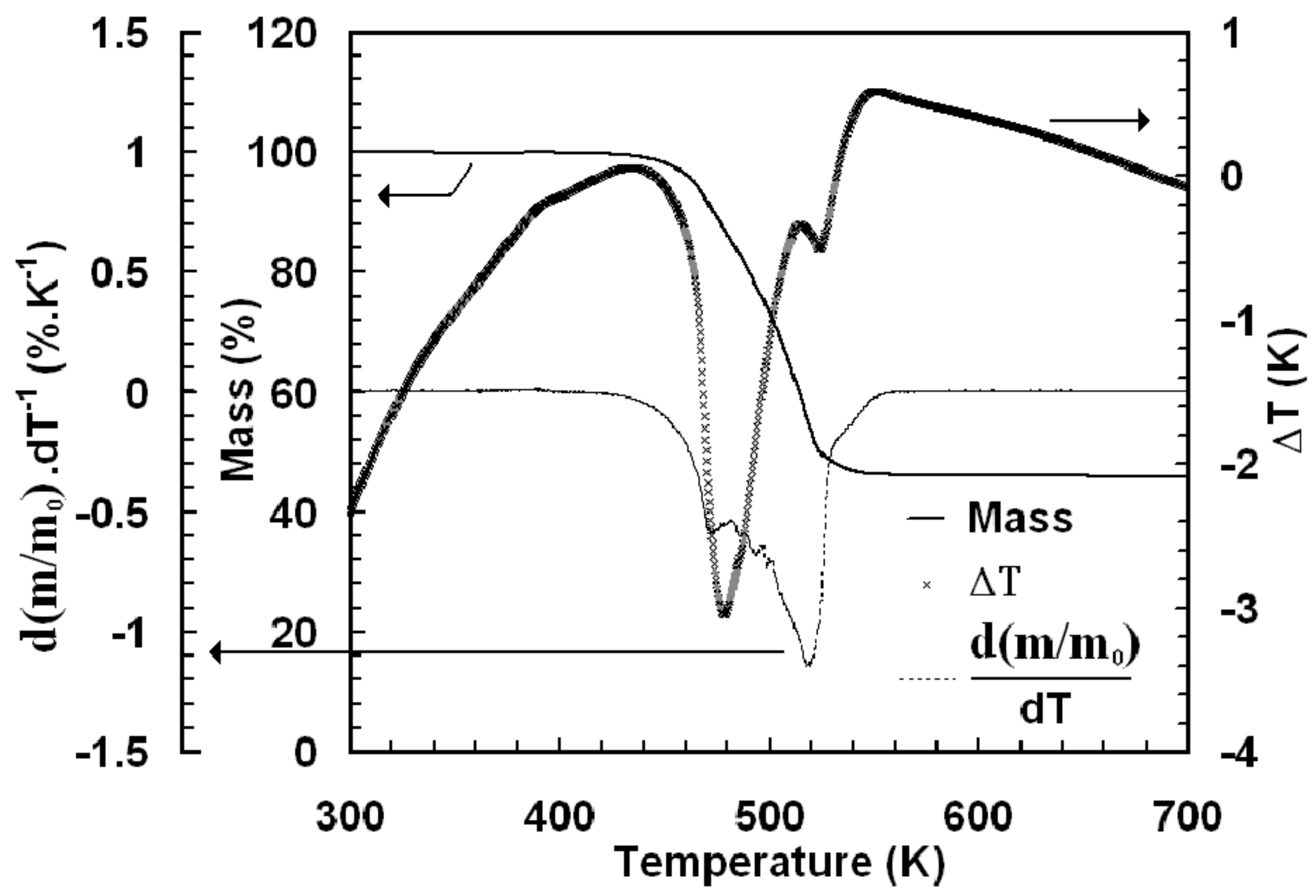




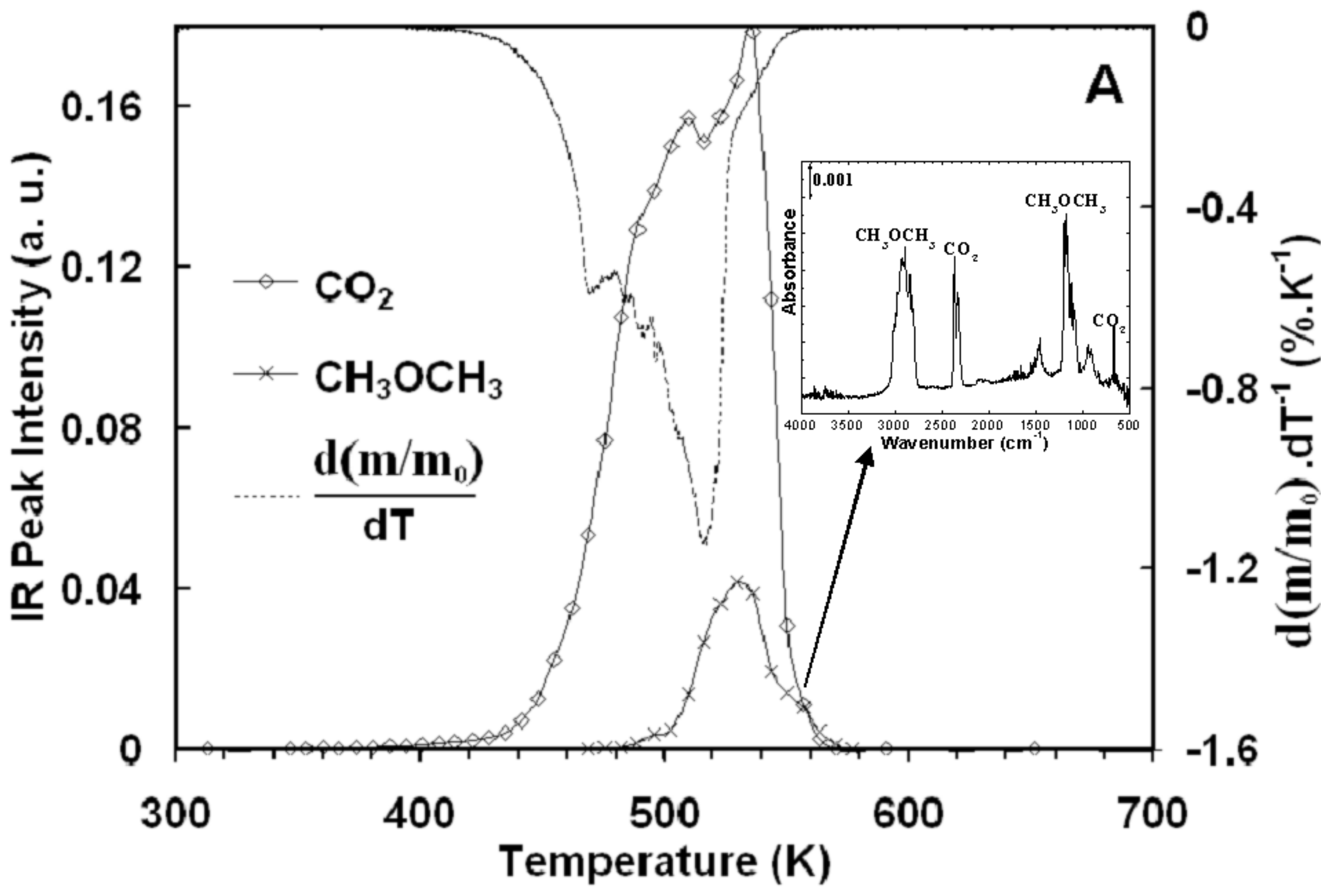




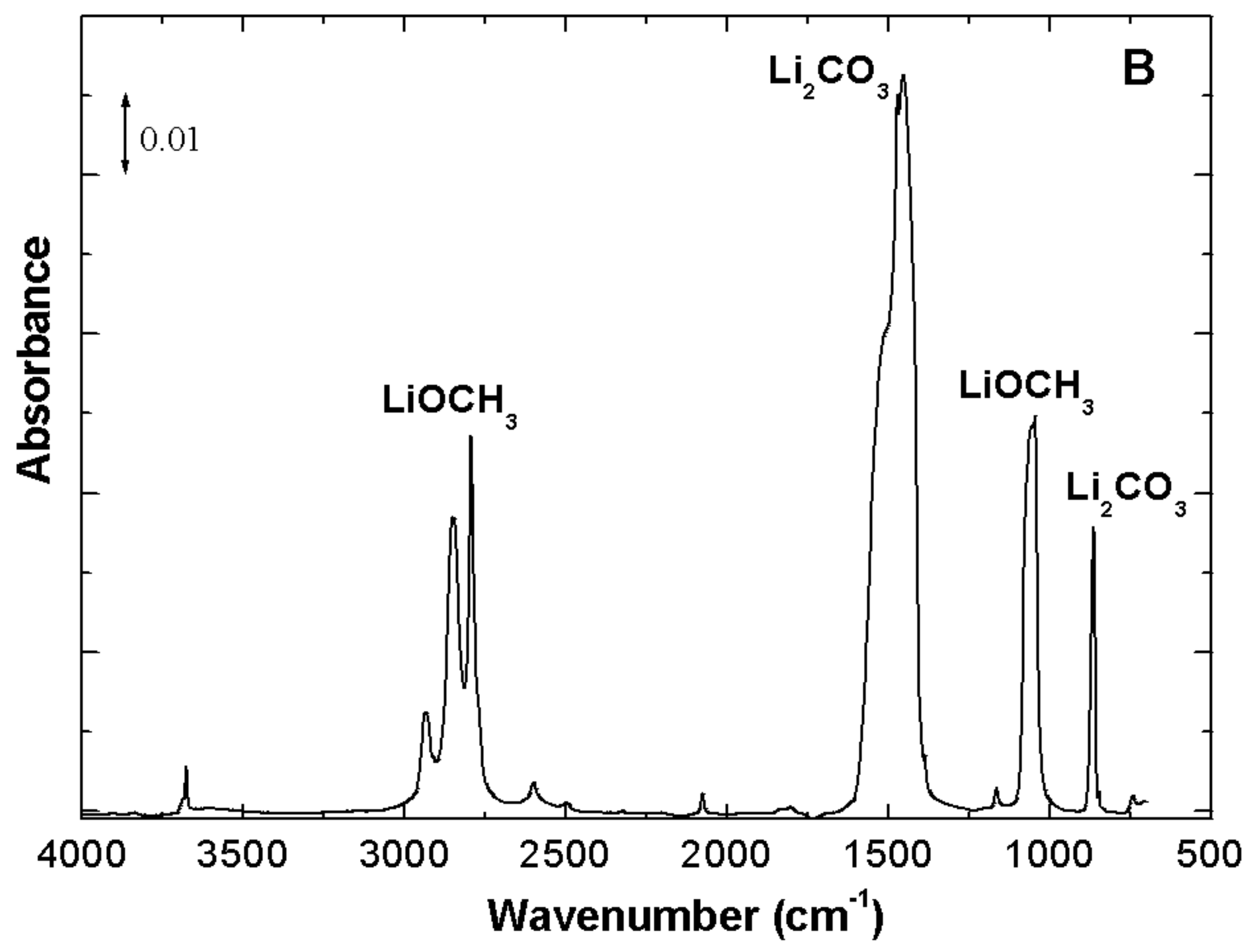

